GU J Sci, Part C, 5(4): 99-107 (2017)

Gazi Üniversitesi
Fen Bilimleri Dergisi
PART C: TASARIM VE TEKNOLOJI
dergipark.gov.tr/http-gujsc-gazi-edu-tr

\title{
Ergonomik Bilgisayar Kullanımına Yönlendiren Bir Asistan Sistem Tasarımı
}

\author{
Hüseyin GÜRÜLER ${ }^{1, *}$, Uğur AYVAZ ${ }^{1}$ \\ ${ }^{l}$ Muğla Sitkı Koçman Üniversitesi, Teknoloji Fakültesi, Bilişim Sistemleri Mühendisliği Bölümü
}

$\ddot{O ̈ z}$

$\underline{\text { Makale Bilgisi }}$

Başvuru: 12 /09/ 2017

Düzeltme: 06/11/2017

Kabul: 22/11/2017

\begin{tabular}{l} 
Anahtar Kelimeler \\
\hline Kinect \\
Ofis ergonomisi \\
Sanal asistan \\
Insan-bilgisayar \\
etkileşimi
\end{tabular}

Keywords

\section{Kinect}

Office ergonomics

Virtual assistant

Human-computer

interaction

\begin{abstract}
Günümüzde hemen her yaş gurubundan insan bilgisayarların ve bilgisayar destekli sistemlerin kullanıcısı konumundadır. Hayatımızı kolaylaştıran teknoloji bir yandan da sağlığımızı tehdit edebilmektedir. Son yıllarda artan bel-boyun ağrıları ve fitık, eklemlerde kireçlenme, görme bozuklukları, obezite gibi rahatsızlıkların bașlıca sebeplerinden bir tanesi de yanlıs bilgisayar kullanımıdır. Bilgisayarların yaygın kullanımı da bu bulguları arttırmaktadır. Bu çalışmanın amacı bilgisayar kullanıcısı bireyleri ergonomik açıdan daha dikkatli bilgisayar kullanmaya yönlendirmektir. Bu amaçla geliştirilen kullanıcı ile etkileşimli sistem, bireylerin bilgisayar kullandıkları süre boyunca ekrana olan uzaklıklarını, ekrana bakış açılarını ve ekrana bakma süresini takip ederek gerekli durumlarda sesli ya da yazllı ikaz vermektedir. $\mathrm{Bu}$ sistemin, bireyleri ergonomik bilgisayar kullanımına teşvik ederek bilgisayar kullanım sıklığından kaynaklı sağlı problemlerini azaltacağı düşünülmektedir.
\end{abstract}

\section{Designing an Assistant System Encouraging Ergonomic Computer Usage}

\begin{abstract}
Today, people of almost every age group are users of computers and computer aided systems. Technology makes our life easier, but it can also threaten our health. In recent years, one of the main causes of the proliferation of diseases such as lower back pain, neck pain or hernia, Arthritis, visual disturbances and obesity is wrong computer usage. The widespread use of computers also increases these findings. The purpose of this study is to direct computer users to use computers more carefully in terms of ergonomics. The user-interactive system developed for this purpose controls distance of the user to the screen and calculates the look angle and the time spent looking at the screen and provides audio or text format warning when necessary. It is thought that this system will reduce the health problems caused by the frequency of computer usage by encouraging individuals to use computers ergonomically
\end{abstract}

\section{GİRIŞ (INTRODUCTION)}

Teknoloji getirdiği yenilikler ve sunduğu kolaylıklarla hayatımızın vazgeçilmez bir parçası haline gelmiştir. Teknolojinin güncel hayatımıza ve iş dünyasına yansımasının en belirgin örneklerinden bir tanesi bilgisayarlar ve bilgisayar destekli sistemlerdir. Ofis ortamlarından, evlerimize kadar, hemen her yerde mevcut olan bu teknoloji ürünlerinin kullanıcısı durumundayız. Bilindiği üzere bilgisayar teknolojisinin sağladığı en büyük yararlardan bir tanesi de eskiden zaman alan işlerin artık tek bir tuşla hızlı bir şekilde yapılabiliyor olmasıdır. Bu açıdan bakıldığında hayatımızı kolaylaştıran teknoloji, yanlış kullanıldığında sağlımızı tehdit eden problemlere de yol açabilmektedir. Günümüzde bilgisayarların yanlış kullanımına bağlı olarak sıkça rastlanan; bel-boyun ağrıları, kireçlenme, görme bozuklukları ve obezite gibi rahatsızlıklar bu problemlere örnek olarak verilebilir. İnsanlar ile bilgisayarların saatler süren bu etkileşimi yeni bilimsel çalışma alanlarının gelişmesinin de önünü açmıştır. İnsan-Bilgisayar Etkileşimi (IBE) son 20 yıldır üzerinde durulan bir bilim dalı olmuştur. Bu bilim dalının getirileri ve kazandırdığ 1 yenilikler de teknolojiye yön vermeye devam etmektedir. İBE'de amaç kullanıcılara daha insancıl gelen, sosyal durumlara karşı tepki verebilen zeki bilgisayarların geliştirilmesidir. Bilgisayarların 
insanc1 olması; insan psikolojine sahip olması ve duygusal davranması anlamlarına gelmektedir. $\mathrm{Bu}$ amaçla duygu tanıma, hareket tanıma, sesli komut tanıma gibi çalışmalar ile bilgisayarlara insansı yetenekler kazandırılmaya çalışılmaktadır. Bilgisayarlar hesaplama ve karmaşık işlemleri yürütmede çok başarılı cihazlardır. Bir de ek olarak insanlara ait yetenekler de kazandırıldığında bilgisayarlar ve bilgisayarlı sistemler zeki insans1 robotlara [1-3] ya da biyomedikal [4-9] ve bilgisayarlı görme [10-11] alanlarda kullanılan sanal asistanlara dönüşmektedir. Asistan niteliğindeki bu sistemler; bilgisayarlardan maksimum düzeyde yararlanırken sağlığımızı da göz ardı etmememizi sağlayan yardımcı sistemlerdir.

$\mathrm{Bu}$ çalışmada özellikle uzun süre bilgisayar kullanan bireylerin bilgisayarlarla olan etkileşimlerine yeni bir boyut kazandıracak yazılım tabanlı bir sistem önerilmektedir. Bu sistemde, kullanıcı ve bilgisayar sürekli etkileşim halindedir ve bireyin hareketleri, duruş postürü, ekrana olan uzaklığı, bilgisayar başında oturma süresi gibi aktiviteleri takip edilerek gerçek zamanlı olarak sesli ya da yazılı uyarılar verilmektedir. Bu çalışmanın asıl amacı; bireyleri ergonomik bilgisayar kullanımına yönlendirmek ve olası sağlık problemlerinin önüne geçmektir. $\mathrm{Bu}$ amaçlarla gerçekleştirilen çalışmanın metodolojik içeriklerinin anlatıldığı bölümde ilk olarak; önerilen sisteme ait yazılım platformundan ve altyapıdan bahsedilmiştir. Ardından geliştirilen yazılıma ait iş-akış diyagramları ve ekran görüntüleri verilerek yapılan iş özetlenmiştir. Sonuç bölümünde ise sistemin kazançlarına değinilerek çalışma tamamlanmıştır.

\section{SISTEMIN ALTYAPISI}

\subsection{Donanımsal Altyapısı}

İBE, çeşitli kamera ve sensörler kullanılarak daha etkili bir şekilde gerçekleşebilmektedir. Bu cihazlar sayesinde insana ait görüntü, ses ya da fizyolojik sinyaller dijital verilere dönüştürülerek bilgisayarlara aktarılır. Bilgisayarlar aldıkları bu dijital verileri çeşitli yazılımlarla değerlendirir, yorumlar ve bir cevap verir. $\mathrm{Bu}$ çalışmada insan-bilgisayar arasındaki etkileșim Microsoft'un Xbox One oyun konsolu için geliştirdiği Kinect sensör (KS) ile sağlanmaktadır. KS'nin ergonomi alanında kullanılabileceğine yönelik çalışmasında Plantard ve diğerleri KS'nin gerçek zamanlı kullanıma uygun olduğunu ve ergonomistleri destekleyen bir teknoloji olduğunu savunmuşlardır [12]. KS, Şekil 1'de görüldüğü gibi 1080 piksel kalitesinde yüksek çözünürlüklü bir RGB kamera, 512x424 piksel boyutlarında derinlik sensörü ve kızılötesi kameralar ile bir dizi mikrofona sahip bir cihazdır.

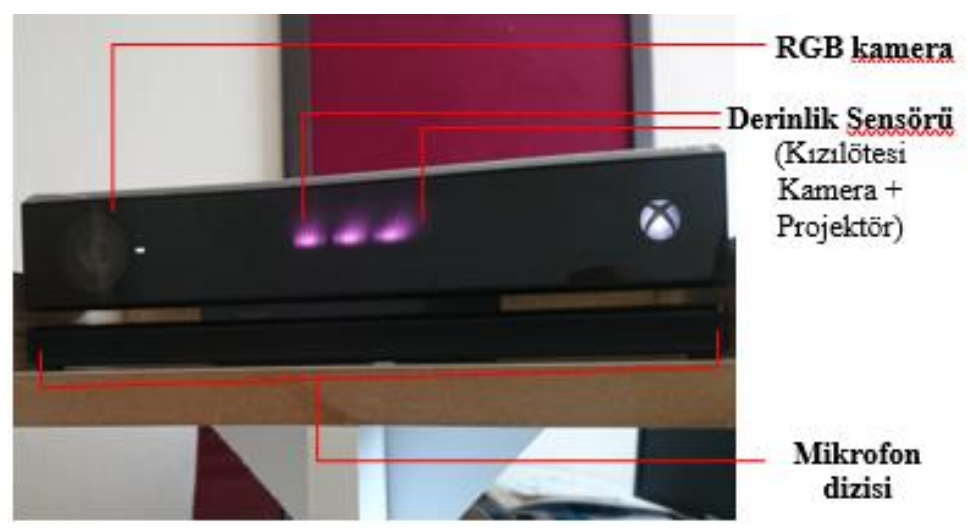

Şekil.1. Kinect Sensör yapısı ve bölümleri (Kinect Sensor structure and parts)

\subsection{Yazılım Altyapısı}

KS'den Microsoft ortamında faydalanabilmek için bir yazılım geliştirme kiti (SDK) mevcuttur. Bu SDK ile Visual Studio ortamında yazılım geliştirmek mümkündür. Bu çalışmada önerilen sistem C\# programlama dilinde bir WPF uygulaması üzerinde tasarlanmıştır. 


\section{METODOLOJI (METHODOLOGY)}

\subsection{Sistemin Çalışma Adımları (Processing Steps of the System)}

Önerilen sistem gerçek zamanlı olarak çalışmaktadır. Bilgisayar kullanıcısı bireyin sağlığı açısından üç aşamalı bir süreç gerçekleşmektedir. İlk olarak bireyin ekrana bakma süresi ve mola tayini gerçekleştirilmektedir. Bu amaçla yüz tespiti ve takibi yapılmaktadır. İkinci aşamada KS nokta bulutu verileri yöntemi kullanılarak ekrana bakma mesafesi ölçümü gerçekleştirilmiştir. Son bölümde ise anlık boyun aç1ları ölçülerek bireyin mümkün olduğu kadar dik ve düzgün bir boyun postüründe kalmas1 yönünde uyarılar gerçekleştirilmiştir.

\subsubsection{Ekrana bakma süresinin düzenlenmesi (Set the screen-viewing time)}

Geliştirilen sistemde bireyin ekrana bakıp bakmadığı yüz tespiti ve takibiyle anlaşılmaktadır. Bu amaçla bilgisayar kullanıcısı birey çalışmaya başladığı andan itibaren KS'ye entegre RGB kamerası ile yüzü takip edilir.

Yüz tespiti işlemi; OpenCV paket yazılımı olan EmguCV kütüphanesi kullanılarak gerçekleştirilmektedir. EmguCV üzerinden Viola-Jones algortiması [13] ile gerçek zamanlı yüz tespiti ve takibi sağlanmıştır. Birey bilgisayar ekranına baktığı sürece yüz tespiti ve takibi gerçekleşir ve ekrana bakma süresi hesaplanır. Bu sayede süre kontrolü ve mola zamanlarının tayini gerçekleştirilerek uzun süre ekrana bakmanın önüne geçilecektir. Geleneksel ergonomide her iki saatte bir 15'er dakikalık molalar vermek gerektiği savunulurken, günümüzde ise bilgisayar karşısında geçirilen sürenin daha kısa tutulması ve bunun yanında daha kısa süreli daha sık molaların verilmesi önerilmektedir [14]. Vücudun sürekli aynı pozisyonda hareketsiz kalması eklemlere zarar verdiği gibi obezite riskini de arttırmaktadır. Ayrıca sürekli ekrana bakmak göz sağlığı açısından zararlıdır. Bu çalışmada önerilen sistem her 15 dakikada bir 30 saniyelik mola verilecek şekilde tasarlanmıştır. Şekil 2'de bu bölüme ait iş akışı verilmektedir.

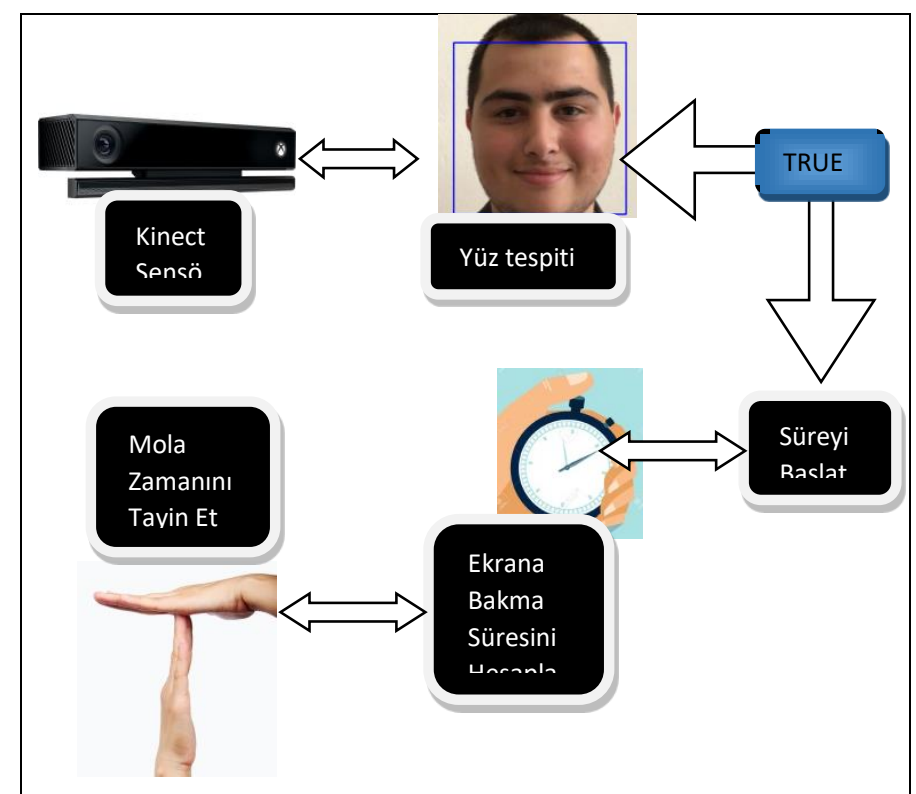

Şekil 2. Ekrana bakma süresi hesaplama ve mola tayini akış diyagramı (The diagram of the screen-viewing time and break-time)

\subsubsection{Ekrana bakma mesafesinin kontrolü (Checking the screen-viewing distance)}

Literatürde, ofis ortamlarında bilgisayar ekranına bakma uzaklığının $40.6-73.1 \mathrm{~cm}$ aralığında olması gerektiği belirtilmiştir [14-16]. KS'nin nokta bulutu yöntemiyle derinlik ve bir nesneye olan uzaklığı ölçmedeki sistematik hata oranı lazer tarayıcının hata oranına göre çok daha azdır [11]. KS, insan 
iskeletine ait 25 adet eklem noktalarının görüntülenmesine ve takibine imkân vermektedir. Şekil 3'te görülen bu noktalardan X, Y ve Z koordinat değerleri elde edilmektedir.

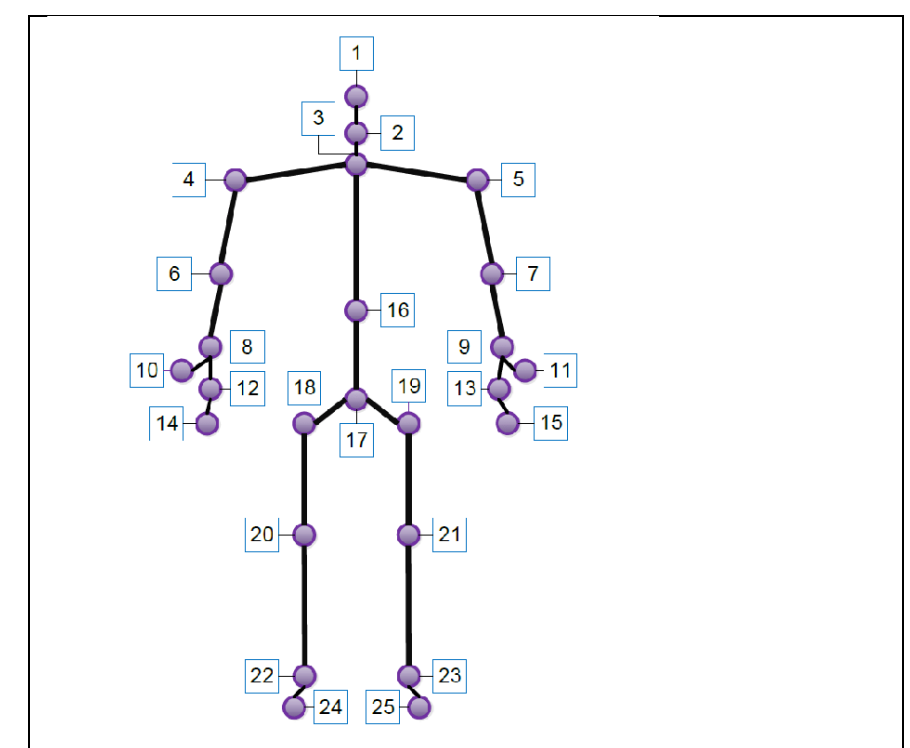

Şekil 3. KS ile takip edilen 25 eklem noktasının iskelet üzerinde gösterimi (Display of 25 joints tracked by $K S$ on the skeleton)

Z koordinatı derinlik mesafesi hesaplamada kullanılan değerdir. Ancak yalnızca Z koordinatı kullanılarak sensöre olan gerçek uzaklığı (SOGU) hesaplamak mümkün değildir. Çünkü Şekil 4'te görüldüğü gibi kullanıcı sensörün tam karşısında olmayabilir.

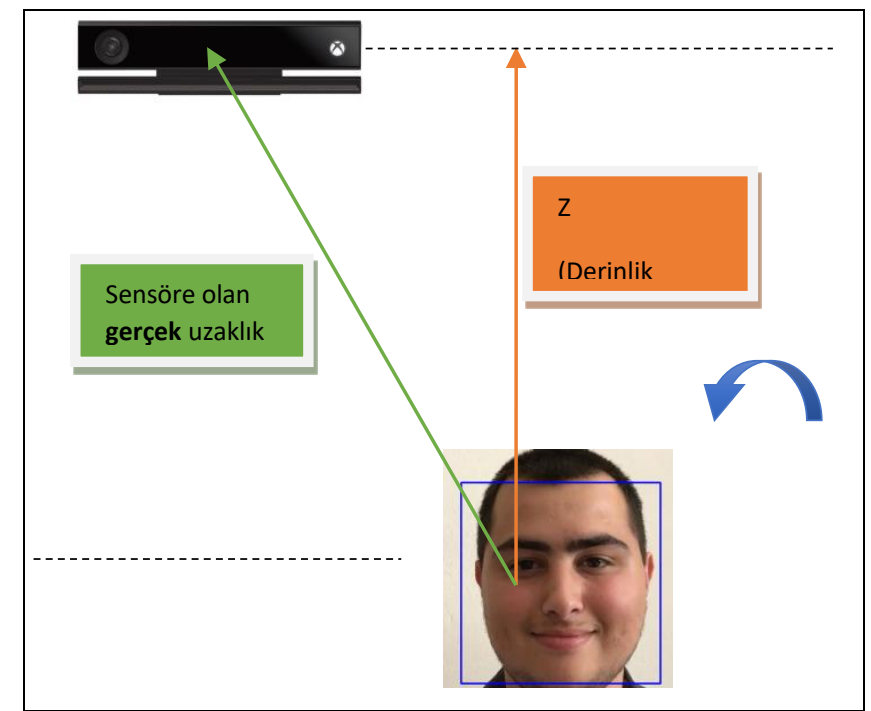

Şekil 4. SOGU değeri ile derinlik mesafesi (Z) arasindaki fark

(The difference between the actual distance to the sensor and the depth distance)

Bu durumda $\mathrm{Z}$ koordinatı derinlik değerini verir ancak SOGU değeri (1) nolu denklemde verildiği gibi hesaplanmaktadir.

$$
S O G U=\sqrt{x^{2}+y^{2}+z^{2}}
$$

$\mathrm{Bu}$ çalışmada Şekil 3'te 1 rakamıyla numaralandırılmış olan baş (head) noktasına göre derinlik hesaplanarak sensöre olan gerçek uzaklık (SOGU) belirlenmiştir. Güncel ergonomide ekrana bakma uzaklığının optimum 0.60 m olması gerektiği savunulmaktadır [17]. KS'nin algılama aralığı ise $0.50 \mathrm{~m}$ ile 
$4.50 \mathrm{~m}$ arasındadır [18]. Gerçekleştirilen deneyler sonucunda KS'nin 0.60 metreden daha yakın mesafelerde ölçüm hassasiyetinin azaldığ 1 ve standart sapmanın arttığ1 görülmüştür. Hem ergonomik açıdan hem de sensör hassasiyeti açısından bireyin ekrana bakma uzaklığ 1 minimum $0.60 \mathrm{~m}$ olarak belirlenmiştir. Birey ekrana $0.60 \mathrm{~m}$ 'den daha fazla yaklaştığında ise sesli ve yazılı uyarı verilerek ikaz edilmiştir.

\subsubsection{Ergonomiye uygun boyun postürünün sağlanması (Providing ergonomic neck posture)}

Bir diğer önemli husus da boyun ağrıları ve fitığa karşı önlem almaktır. Bu amaçla boyun postürünün doğruluğu denetlenmiştir. Ergonomiye uygun boyun postürünün belirlenmesinde; Hizlı Üst Ekstremite Değerlendirmesi (RULA) yöntemindeki boyun açısı değerleri baz alınmıştır. RULA'da [19] üst ekstremitenin ergonomik açıdan duruşu 1-6 aralığında puanlandırılmaktadır. Buna göre ergonomiye en uygun boyun postürü; baş-boyun-göğüs kafesi açısının $180^{\circ} \pm 10^{\circ}$ olduğu duruştur ve "+1" olarak puanlandırılmıştır. Şekil 5'te görüldüğü gibi boynun öne ya da arkaya bükülmesi durumunda risk seviyesi artmaktadır.

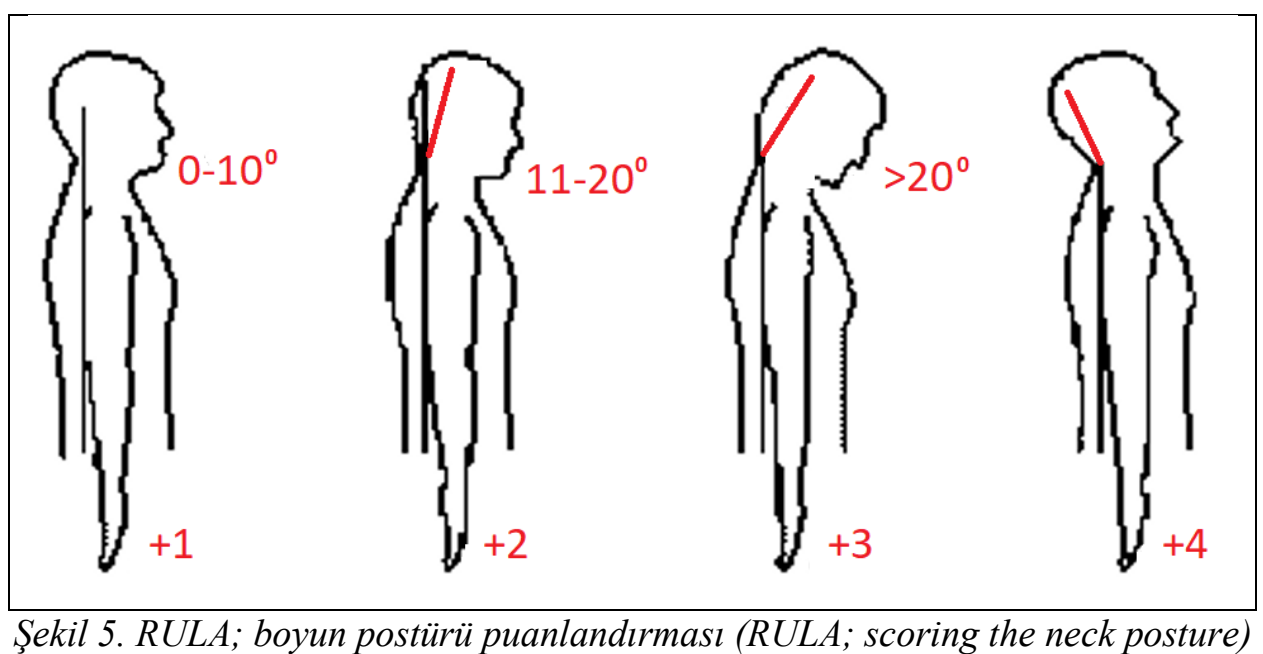

$\mathrm{Bu}$ çalışmada, düzgün bir boyun postürünü belirleyebilmek için iki önemli değer hesaplanmıştır. Bunlardan birincisi başın öne ya da arkaya eğimi, ikincisi ise boynun sağa ya da sola eğimidir. Bu değerler hesaplanırken RULA'daki $10^{\circ}$ 'lik eşik değeri dikkate alınmıştır.

Başın öne ya da arkaya eğimini hesaplamak için;

- (1) nolu denklemde verilen SOGU değeri yüz ve boyun noktalarına ait X, Y, Z koordinatları için ayrı ayr1 hesaplanır.

$$
\begin{gathered}
\operatorname{SOGU}_{\text {bas }}=\sqrt{X_{1}^{2}+Y_{1}^{2}+Z_{1}^{2}} \\
\operatorname{SOGU}_{\text {boyun }}=\sqrt{X_{2}^{2}+Y_{2}^{2}+Z_{2}^{2}}
\end{gathered}
$$

- Bu iki SOGU değeri arasındaki farkın mutlak değeri hesaplanır.

$$
D_{1}=\left|S O G U_{\text {bas }}-S O G U_{\text {boyun }}\right|
$$

- Trigonometrik hesap ile (4) nolu denklemde elde edilen $D_{1}$ değeri $3.8 \mathrm{~cm}$ ve daha büyükse, baş öne ya da arkaya $10^{\circ}$ 'den fazla eğiktir ve bu durumlarda uyarı verilerek kullanıcı ikaz edilir. 
- Diğer bir ifadeyle başın nötr konumdayken sensöre olan uzaklığ $b_{0}$, baş öne eğikken sensöre olan uzaklık $b_{1}$ olsun. Bu durumda; $b_{0}-b_{1} \geq 2.5 \mathrm{~cm}$ ise baş öne $10^{\circ}$ 'den fazla eğiktir ve kullanıcı ikaz edilir.

Boynun sağa ya da sola eğimini açısal olarak hesaplamak için ise KS ile takip edilen Şekil 3'teki 1, 2 ve 3 numaralı noktalar kullanılmıştır. Düzgün bir boyun postüründe; baş-boyun ve gögüs kafesi çizgisi arasındaki açısının $180^{\circ}$ olması yani başın nötr pozisyonda olması gerekmektedir [14, 17]. Önerilen sistem bu açının maksimum $\% \pm 10$ derece sağa ya da sola sapmasına tolerans gösterecek şekilde ayarlanmıştır. Şekil 6' da $205^{\circ}$ 'lik bir açıyla sağa eğilmiş hatalı bir boyun postürü gösterilmektedir.

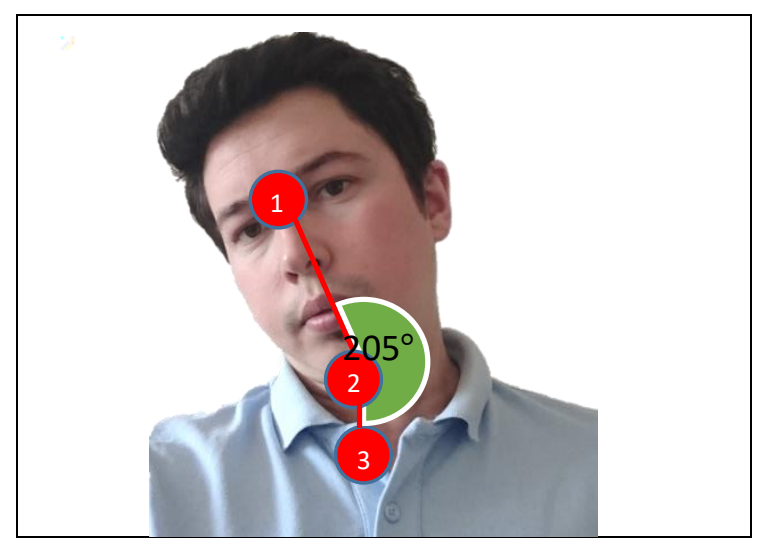

Şekil 6. Ergonomik olmayan boyun postürüne bir örnek (An example of unergonomic neck posture)

\section{SONUÇ ve DEĞERLENDİRMELER (RESULTS and EVALUATION)}

Kinect sensörün ölçüm hassasiyetini belirlemek amacıyla, yazılım tarafından hesaplanan değerler gerçek ölçümlerle kıyaslanarak değerlendirme yapılmıştır. Bu amaçla 10 farklı bireyin katılımıyla sistem test edilmiştir. Buna göre Tablo 1 ve Tablo 2 'deki değerler elde edilmiştir.

Tablo 1. Sensöre olan uzaklı̆ğn deneysel ölçülmesi

(Experimental measurement of the distance from the sensor)

\begin{tabular}{|c|lllll|}
\hline Katılımcı & \multicolumn{5}{|c|}{ Sistemin Ölçüm değerleri (cm) } \\
\hline 01 & 61,85 & 70,48 & 81,75 & 93,07 & 100,79 \\
02 & 60,92 & 70,65 & 82,132 & 90,22 & 102,5 \\
03 & 60,24 & 69,97 & 79,71 & 90,45 & 99,93 \\
04 & 62,24 & 70,58 & 80,27 & 90,24 & 100,4 \\
05 & 64,45 & 70,65 & 80,32 & 90,42 & 100,08 \\
06 & 63,97 & 70,03 & 82,89 & 92,24 & 102,2 \\
07 & 63,49 & 70,002 & 80,29 & 90,18 & 100,9 \\
08 & 63,34 & 70,56 & 80,43 & 89,54 & 101,3 \\
09 & 61,82 & 69,73 & 80,34 & 90,12 & 100,6 \\
10 & 64,06 & 70,09 & 80,97 & 91,04 & 99,85 \\
\hline Ortalama & 62,538 & 70,2742 & 80,8202 & 90,649 & 100,88 \\
\hline Standart Sapma & 1,3542 & 0,3426 & 1,0478 & 1,1042 & 0,8826 \\
\hline Gerçek Ölçüm & 60 & 70 & 80 & 90 & 100 \\
\hline
\end{tabular}

Tablo 1'de görüldüğü gibi önerilen sistem SOGU ölçümünde oldukça başarılıdır. Ayrıca SOGU, 62 cm'nin altına düştügünde sistemin ölçümlerindeki standart sapma artmaktadır. Bu durum, sistem hassasiyetinin sensöre yaklaşıldıkça azaldığını göstermektedir. 
Tablo 2. Boyun Açısının Deneysel Ölçülmesi (Experimental measurement of the neck angle)

\begin{tabular}{|c|lllll|}
\hline Katılımcı & \multicolumn{5}{|c|}{ Sistemin Ölçüm değerleri ( ${ }^{\circ}$ ) } \\
\hline 01 & 159 & 176 & 180 & 194 & 203 \\
02 & 157 & 170 & 181 & 188 & 204 \\
03 & 153 & 171 & 179 & 193 & 206 \\
04 & 156 & 174 & 182 & 191 & 205 \\
05 & 161 & 172 & 178 & 187 & 206 \\
06 & 156 & 172 & 181 & 186 & 199 \\
07 & 158 & 169 & 180 & 187 & 202 \\
08 & 154 & 170 & 180 & 188 & 204 \\
09 & 155 & 168 & 179 & 189 & 200 \\
10 & 150 & 172 & 180 & 189 & 208 \\
\hline Ortalama & 155,9 & 171,4 & 180 & 189,2 & 203,7 \\
\hline Standart Sapma & 3,1429 & 2,3664 & 1,1547 & 2,6583 & 2,7909 \\
\hline Gerçek Ölçüm & 155 & 170 & 180 & 190 & 205 \\
\hline
\end{tabular}

Tablo 2'deki deneysel veriler, sensöre olan uzaklık sabit tutulmak kaydıyla $(65 \mathrm{~cm})$; bireylerin boyun açıları KS tarafından hesaplanarak elde edilmiştir. Tablodan anlaşılacağı üzere sistemin standart sapması maksimum $3.14^{\circ}$ olarak görülmektedir. Boyun açısı $180^{\circ}$ den uzaklaştıkça (açıda artma ya da azalma) hata oranı da yükselmiştir. Ayrıca sensöre olan uzaklık arttıkça özellikle $80 \mathrm{~cm}$ ve üzerinde standart sapmanın arttığı görülmüştür. Sonuç olarak elde edilen sisteme ait arayüz görüntüsü Şekil 7'de verilmektedir.

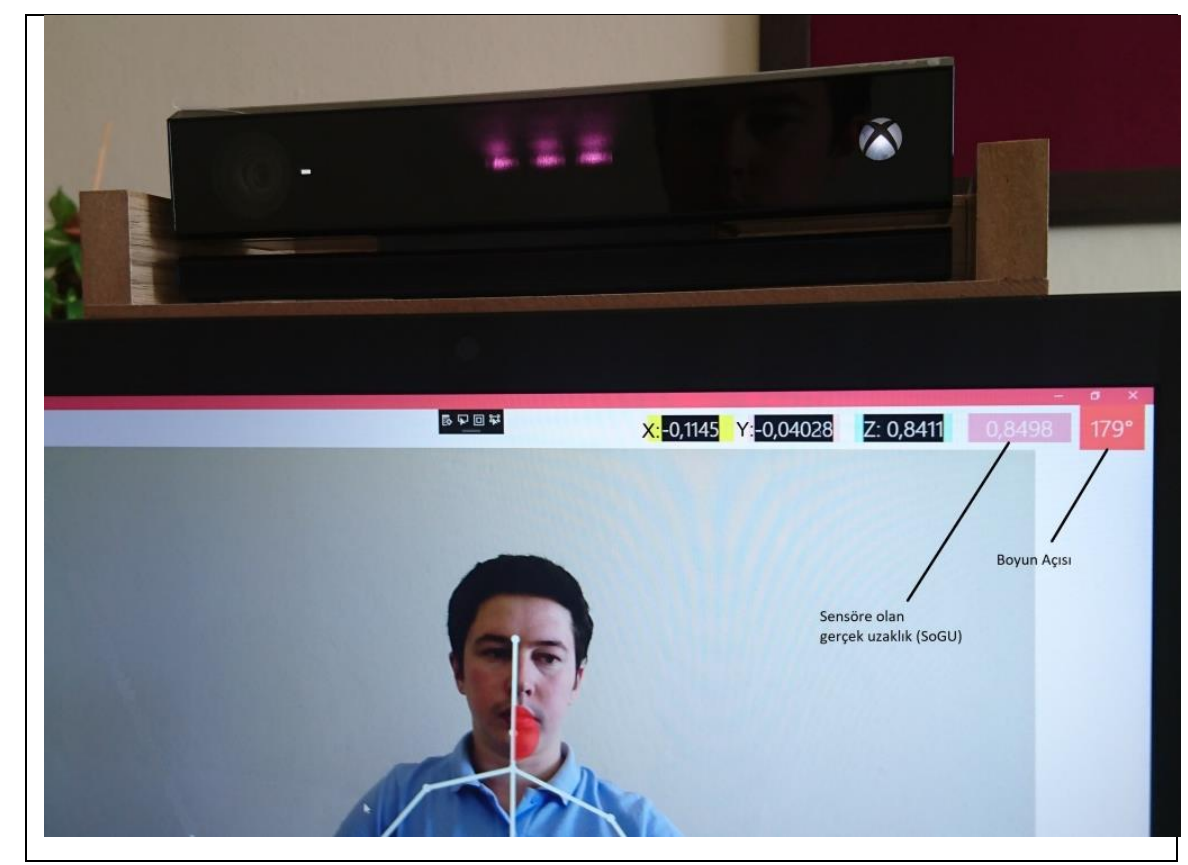

Şekil 7. Boyun açısl ve ekrana olan uzaklı̆̆ın gösterildiği bir arayüz

(An interface that shows the neck angle and the distance to the screen)

Daha önce belirtildiği gibi KS'nin minimum ve maksimum algilama mesafeleri sirasıyla $0.50 \mathrm{~m}$ ve 4.50 m'dir. Sistem çalışmaktayken bu mesafe aralığının dışına çıkılması durumunda KS kullanıcıyı algılayamadığından düzgün çalışmayacaktır. Bu durumu engellemek amacıyla bu sınır mesafelerine yaklaşıldığında sistem tarafından uyarı verilmektedir. Uyarı eşik değerleri, minimum $0.60 \mathrm{~m}$ (ki aynı zamanda ekrana olan minimum uzaklık sınırı), maksimum ise $1.50 \mathrm{~m}$ olarak ayarlanmıştır. 
Duruş postürü ne kadar düzgün olursa olsun bireyler belirli aralıklarla postür değiştirmeyi alışkanlık haline getirmelidir. Ergonomi kuralları doğrultusunda ekrana kesintisiz bakma süresi maksimum $15 \mathrm{dk}$ olarak belirlenmiş bu süre aşılması durumunda sistem tarafından uyarı verilerek 30 sn'lik mola tayin edilmiştir. Buradaki amaç bireyin uzun süreli ekrana bakmasını önlemektir. Mevcut sistemde, ekrana bakma süresinin hesaplanmasının en önemli şartı yüz tespiti ve takibinin gerçekleşmesidir. Yüz tespiti ve takibi gerçekleştiği sürece sistem sorunsuz çalışmaktadır. Yüz tespiti gerçekleşmediği durumda örneğin; kullanıcının 1-2 sn’lik kısa süreli olarak yüzünü farklı yönlere çevirmesi durumlarında sistem, ekrana bakma süresini sıfırlamaktadır. Bu durumda gerçek ekrana bakma süresi hesaplanamamaktadır, çünkü birey her 14 dakikada bir, 1-2 saniyeliğine yüzünü çevirebilir ve bu durumda 15 sn'lik süre sınırı tamamlanmadığından mola tayini verilemeyecektir. Bu probleme çözüm olarak; yüz tespitinin gerçekleşmeme süresi $10 \mathrm{sn}$ den fazla ise süre sıfirlanacak ve mola verildiği düşünülecek aksi takdirde ekrana bakma süresi devam ettirilecek ve $15 \mathrm{dk}$ sonunda mola verdirilecektir.

$\mathrm{Bu}$ çalışma ile elde edilen deneysel sonuçlar sistemin, ergonomik bilgisayar kullanımına katkı sağlayacağı fikrini destekler niteliktedir. Ayrıca önerilen sistem, ofis ortamlarında insan-bilgisayar arasındaki etkileşimi düzenleyerek bireylerin daha ergonomik bir ortamda daha verimli çalışabilmelerine imkân sağlayacak prototip bir sistemdir. Gelecek çalışmalarda bu sistemin bireyleri ergonomik kullanıma yönlendirmede başarılı olup olmadığı daha uzun süreli kullanıcı deneyimleriyle ölçülerek sistem değerlendirmesi yapılabilir.

\section{TEŞEKKÜR (ACKNOWLEDGMENT)}

Bu çalışma, Muğla Sitk1 Koçman Üniversitesi, Bilimsel Araştırma Projeleri Koordinatörlüğü, 16/129 nolu yüksek lisans tez projesi kapsamında desteklenmektedir.

\section{KAYNAKLAR (REFERENCES)}

[1] El-Iaithy, R.A., Jidong, H., Yeh, M., "Study on the Use of Microsoft Kinect for Robotics Applications.", In Proceedings of the Position Location and Navigation Symposium (PLANS), Myrtle Beach, SC, USA, pp. 12801288, 23-26 April 2012.

[2] Oliver, A., Kong, S., Wünsche, B., MacDonald, B., "Using the Kinect as a Navigation Sensor for Mobile Robotics.", In Proceedings of the 27th Conference on Image and Vision Computing (IVCNZ'12), Dunedin, New Zealand, pp. 505-514, 26-28 November 2012.

[3] Suarez, J., Murphy, R.R., "Using the Kinect for Search and Rescue Robotics.", In Proceedings of the IEEE International Symposium on Safety, Security, and Rescue Robotics (SSRR), College Station, TX, USA, pp. 12, 5-8 November 2012.

[4] Guevara, D.C., Vietri, G., Prabakar, M., Jong-Hoon K., "Robotic Exoskeleton System Controlled by Kinect and Haptic Sensors for Physical Therapy.", In Proceedings of the 29th Southern Biomedical Engineering Conference (SBEC), Miami, FL, USA, pp. 71-72, 3-5 May 2013.

[5] Kastaniotis, D., Economou, G., Fotopoulos, S., Kartsakalis, G., Papathanasopoulos, P., "Using Kinect for Assessing the State of Multiple Sclerosis Patients.”, In Proceedings of the 2014 EAI 4th International Conference on Wireless Mobile Communication and Healthcare (Mobihealth), Athens, Greece, pp. 164-167, 35 November 2014.

[6] Bravo, C. B., Ojeda-Castelo, J. J., \& Piedra-Fernandez, J. A., "Art activities with Kinect to Students with Cognitive Disabilities: Improving all Motor Skills.”, Procedia-Social and Behavioral Sciences, 237, pp. 1148$1151,2017$.

[7] Ulrich, D., Farra, S., Smith, S., \& Hodgson, E., "The student experience using virtual reality simulation to teach decontamination.", Clinical Simulation in Nursing, 10(11), pp. 546-553, 2014.

[8] Chang, Y. J., Chen, S. F., \& Huang, J. D., “A Kinect-based system for physical rehabilitation: A pilot study for young adults with motor disabilities.", Research in developmental disabilities, 32(6), pp. 2566-2570, 2011. 
[9] Pedraza-Hueso, M., Martín-Calzón, S., Díaz-Pernas, F. J., \& Martínez-Zarzuela, M., "Rehabilitation using kinect-based games and virtual reality.”, Procedia Computer Science, 75, pp. 161-168, 2015.

[10] Li, B. Y., Xue, M., Mian, A., Liu, W., \& Krishna, A., "Robust RGB-D face recognition using Kinect sensor.”, Neurocomputing, 214, pp. 93-108, 2016.

[11] Khoshelham, K., “Accuracy Analysis of Kinect Depth Data.”, In Proceedings of the International Archives of the Photogrammetry, Remote Sensing and Spatial Information Science, Calgary, Alberta, CA, pp. 133-138, 29-31 August 2011.

[12] Plantard, P., Muller, A., Pontonnier, C., Dumont, G., Shum, H. P., \& Multon, F., "Inverse dynamics based on occlusion-resistant Kinect data: Is it usable for ergonomics?.”, International Journal of Industrial Ergonomics, 61, pp. 71-80, 2017.

[13] P. A. Viola, M. J. Jones, "Rapid object detection using a boosted cascade of simple features", IEEE Computer Society Conference on Computer Vision and Pattern Recognition CVPR 2001, 511-518, 2001.

[14] Office Ergonomics Advisory Committee, "Office Ergonomics, practical solutions for a safer workplace", WISHA Services Division, Washington State Department of Labor and Industries, 2002.

[15] Seçkiner, S. U., \& Kurt, M., “Ofis Güvenliğinin Değerlendirilmesi İçin Geliştirilmiş Ergonomi Teknolojisi: Kairos, Örnek Uygulama”, Gazi Üniversitesi Mühendislik-Mimarlık Fakültesi Dergisi, 19(1), 2004.

[16] Baslo, M., “Ofis Ergonomisi-Sırt ve Boyun Ağrılarını Önlemek İçin Ofis Ortamını Düzenlemek”, Baş, Boyun, Bel Ağrıları Sempozyum Dizisi, (30), 155-165, 2002.

[17] Kroemer, A. D., \& Kroemer, K. H., “Office Ergonomics: Ease and Efficiency at Work.”, CRC Press., 2016.

[18] Pagliari, D., \& Pinto, L., "Calibration of kinect for xbox one and comparison between the two generations of microsoft sensors.”, Sensors, 15(11), pp. 27569-27589, 2015.

[19] Lueder, R., \& Corlett, N., “A proposed RULA for computer users.”,Proceedings of the ergonomics summer workshop, UC Berkley Center for Occupational and Environmental Health Continuing Education Program San Francisco, pp. 8-9, 1996. 